\title{
Studies on Blight of Tomato Incited by Rhizoctonia solani
}

\author{
N. Sumalatha*, B. Pushpavathi, R. Jagadeeshwar and R.V.S.K. Reddy \\ ${ }^{1}$ Department of Plant Pathology, Acharya N G Ranga Agricultural University, \\ ${ }^{2}$ Horticulture, YSRHU, Rajendranagar, Hyderabad-500030, India \\ *Corresponding author
}

\section{Keywords \\ Blight, Pathogenicity, Rhizoctonia, Rootdip Inoculation, Soilinfestation, Stem application, Tomato \\ Article Info \\ Accepted: \\ 10 February 2018 \\ Available Online: \\ 10 March 2018}

\section{A B S T R A C T}

Tomato is one of the most important vegetable crops cultivated for its fleshy fruits. Rhizoctonia solani is the most important soilborne pathogen of tomato crop and in recent past it is known to cause blight symptoms on stems of tomato plants which has become a serious threat to tomato cultivation in Ranga Reddy district of Andhra Pradesh. The pathogen was isolated on PDA from blight affected tomato plants collected from farmers' fields and was identified as Rhizoctonia solani based on its cultural and morphological characteristics. The culture of the fungus was greyish white in the beginning which later turned to black in color with cottony aerial mycelial growth. The hyphae produced branches mostly at right angles with constriction at the origin of branch and often formed a septum near the branch origin. The fungus produced microsclerotia of $0.8-1.0 \mathrm{~mm}$ in size in sixty days old cultures. Of the three inoculation methods, root dip inoculation was found to be the best as it resulted in maximum per cent disease incidence (96.67) in a short period of incubation (two days). Symptoms produced due to soil infestation and root dip inoculation appeared as typical damping off symptoms with dark brown lesions at the collar region and yellowing of leaves which lead to death of seedlings. Whereas, in case of stem application the initial symptoms appeared as water soaked lesions on stems which later became oval to irregular light brown necrotic spots. Mature spots on stems appeared as large brown blighted portion with typical cracks on the bark. In advanced stages plant collapsed at infected portion leading to death of the plant.

\section{Introduction}

Plant diseases constitute a major constraint to crop production often resulting in a great degree of crop losses which may range from slight to 100 per cent (Agrios, 2005).

Diseases of tomato caused by fungi, bacteria, viruses, and nematodes can be severe, reduce tomato yield and quality wherever the crop is grown. Among fungal diseases that attack tomato crop early blight, late blight, leaf spots, anthracnose, buckeye rot, wilts and root rots are found to be the important diseases (Andy Wyenandt, 2005). However, the root rot caused by Rhizoctonia solani is the most devastating and destructive disease of tomato and became the major constraint to the profitable production of tomato in India. It was also reported that, the root rot pathogen along with a nematode Melodogyne incognita could cause $38.64-56.74$ per cent yield loss 
in tomato (Kumar and Singh, 2006a,b; Upadhyay and Dwivedi, 2008). As Rhizoctonia solani is a soilborne pathogen, the disease caused by it is difficult to manage due to its exceptionally broad host range that includes over 500 plant species including tomato. On the other hand, management of this disease is difficult not only due to its wide host range and soilborne nature but also the long saprophytic survival ability of the pathogen in soil (Kumar et al., 2011).

In tomato, in addition to root rot Rhizoctonia solani was also reported to cause stem canker (Wokoma, 2008) and damping off (Dutta and Dutta, 2007) and is considered to be the most important soilborne disease of tomato causing severe losses under favourable conditions at nursery beds. Apart from this the fungus was also known to cause root and crown rot incidence under greenhouse conditions (Latorre and Bernardo, 2004).

Though damping off caused by Rhizoctonia solani in tomato is very common to see in nurseries, an increased incidence of blight caused by Rhizoctonia solani was noticed in recent past in major tomato growing areas of Ranga Reddy district of Andhra Pradesh. The disease was found to appear predominantly during early transplanted to flowering and fruiting stage of the crop causing considerable loss to the crop both in terms of plant stand and yield. However, the disease incidence varied from 12.8 to $33.2 \%$ during 2011-12 rabi season under natural field conditions (Pushpavathi et al., 2013).

Keeping the increased incidence of blight on tomato in view, the present study was planned to conduct a systematic study on this disease.

The main objectives of this study includes to Proving pathogenicity of Rhizoctonia solani at different growth stages of crop.

\section{Materials and Methods}

Isolation and maintenance of test pathogen

The pathogen was isolated from tomato plants showing typical blight symptoms under field conditions. Stems showing typical symptoms were washed under running tap water for few minutes. Blight affected stem portions were made into $3-5 \mathrm{~mm}$ sized bits and were surface sterilized with 1 per cent sodium hypochlorite for 30 seconds followed by rinsing in three changes of sterile distilled water to remove the traces of sodium hypochlorite. These stem bits were transferred to PDA medium in Petri plates and kept for incubation at $26 \pm 2{ }^{\circ} \mathrm{C}$. When the growth of the fungus from the infected bits was seen on the agar surface, the hyphal bits from the periphery of the culture growing in the Petri plates were transferred to PDA slants in culture tubes.

\section{Purification}

The culture was purified by adopting hyphal tip method (Rangaswami and Mahadevan, 1999). Pure culture of the organism was maintained on PDA by periodical subculturing.

\section{Identification of the Pathogen}

The fungus associated with the disease was obtained in pure form on PDA medium and identified based on its morphological and cultural characteristics (Barnett and Hunter, 2003 and Rifai, 1969).

\section{Pathogenicity tests}

Pathogenicity tests were conducted using Arka vikas a highly susceptible cultivar of tomato. The tests were performed under glasshouse conditions by adopting three different inoculation methods viz., soil infestation, root dip inoculation, stem application. Of these soil 
infestation was done at the time of sowing, root dip inoculation was done at transplantation, while the stem application was done at 15 DAT (Days After Transplantation), 30 DAT, 45 DAT and 60 DAT. Suitable controls were maintained for all the inoculation methods.

\section{Mass multiplication of the pathogen}

\section{Multiplication on sorghum grains}

To prove pathogenecity, the pathogen was multiplied on sorghum grains (Gupta and Kolte, 1982). For this, sorghum grains were pre-soaked in two per cent sucrose solution for about overnight, drained and boiled in fresh water for 30 minutes and drained again. This was transferred into $1000 \mathrm{ml}$ flasks @ $400 \mathrm{~g}$ per flask and autoclaved at 15 PSI $\left(121.6^{\circ} \mathrm{C}\right)$ for 20 minutes. The flasks were allowed to cool at room temperature and inoculated with five $\mathrm{mm}$ discs of seven days old culture of Rhizoctonia solani grown on PDA and flasks were incubated for ten days at $26 \pm 2{ }^{0} \mathrm{C}$.

\section{Multiplication in PDB}

Five mm discs of seven days old culture of $R$. solani were added to $100 \mathrm{ml}$ PDB in $250 \mathrm{ml}$ conical flasks. These flasks were incubated about 14 days on a rotary shaker at $80-100$ rpm and optimum growth temperature.

\section{Preparation of mycelial suspension}

The mycelial mat of the pathogen formed on PDB was separated by using a sieve and washed repeatedly with sterile distilled water. Excess water was drained by applying gentle pressure onto the mycelium. Five grams of this mycelial mat was added to one liter of sterile distilled water and stirred constantly. The homogenized suspension thus prepared was used for inoculation immediately (Buttner et al., 2004).

\section{Soil infestation}

To the pots filled with sterile soil $(15 \mathrm{~cm}$ diameter) $50 \mathrm{~g}$ of the $R$. solani mass multiplied on sorghum grain and ground into a fine powder in a mixer-grinder was applied uniformly. Immediately after inoculation the pots were sprinkled with water, covered completely with a polythene sheet and tied tightly with the help of a thread. These pots were left on a glasshouse bench for incubation. On the third day the polythene sheet was removed and the pots were observed for the development of mycelial mat on the soil surface (Naz et al., 2008).

Seeds of tomato cultivar Arka vikas were sown into the infested soil in pots@ 050 seeds per pot. Two such pots were maintained for each replication. After germination seedlings were observed daily for symptom expression. The typical symptoms of the disease observed were recorded. The data on total number of seedlings and number of affected seedlings were recorded to calculate per cent disease incidence (PDI).

PDI was calculated by adopting following formula:

PDI $=\frac{\text { Number of plants affected }}{\text { Total number of plants }}$

The pathogen was reisolated from the infected seedlings and the culture obtained was compared with the original culture in all respects.

\section{Root dip inoculation}

Seedlings of Arka vikas were raised in pots $(15 \mathrm{~cm}$ diameter) filled with sterilized soil. Twenty eight days old seedlings were uprooted from the pots carefully, washed with sterile distilled water to remove the excess soil 
present on the root surface and the distal one third of root system was trimmed. These trimmed seedlings were dipped in mycelial suspension of the pathogen for ten minutes and then transplanted to pots filled with sterile potting mixture. For each replication 100 trimmed seedlings were inoculated. Transplanted seedlings were watered regularly.

After transplantation, seedlings were observed daily for the presence of typical symptoms. The pathogen was reisolated from the infected seedlings and the culture obtained was compared with the original culture.

The data on total number of seedlings and number of affected seedlings were recorded to calculate per cent disease incidence.

\section{Stem application}

The seeds of tomato cultivar Arka vikas were sown in pots $(30 \mathrm{~cm}$ diameter) filled with sterilized soil. For proving pathogenecity by stem application method at 15,30, 45 and 60 days after transplanting, seedlings were raised in separate pots with 15 days regular intervals. Twenty eight days old seedlings were uprooted from the pots in which they were sown and were transplanted into fresh pots of same size filled with strerile soil and watered regularly. The mycelial suspension was applied with the help of camel hair brush @ $5 \mathrm{ml}$ per each seedling at 15, 30, 45 and 60 days after transplantion. Immediately after inoculation, the inoculated stem portions were wrapped with blotter papers and the pots were watered regularl, y. Two days after inoculation the blotter paper wrappers were removed and the seedlings were observed daily for the presence of symptoms.

The pathogen was reisolated from the infected seedlings and the culture obtained was compared with the original culture. The data on total number of seedlings and number of affected seedlings were recorded to calculate per cent disease incidence.

\section{Results and Discussion}

\section{Isolation of pathogen}

Pathogen was isolated from the blight affected tomato plant portions on potato dextrose agar (PDA) and the pure culture was obtained by adopting hyphal tip method. Isolated pathogen was confirmed as Rhizoctonia solani by observing the cultural and morphological characteristics of the fungus. The colonies formed were grayish white in the beginning which later turned to black in colour with cottony aerial mycelial growth (Plate 1) and showed slow growth habit. It took 10 days to get full growth in $90 \mathrm{~mm}$ Petri plates. The results are in conformity with the findings of Tredway and Burpee (2001) who reported that the colonies of $R$. solani on PDA ranged in colour from buff to black. Kaore et al., (2012) while working with $R$. solani also observed the cottony wooly growth progressing to greyish-white to shiny metallic black colonies. However, the slow growth rate of the fungus on culture medium was in contrast with findings of Domand and Flentje (1970) wherein the growth rate of $R$. solani was very rapid and a typical isolate can grow across a $90 \mathrm{~mm}$ Petri plate in three days.

Sixty days after full growth of the pathogen on PDA in Petri plate it formed microsclerotia which were round to oval in shape and 0.8-1.0 $\mathrm{mm}$ in diameter with dark brown to black in colour (Plate 4.4). Evidences also exist for the formation of irregularly shaped and light tan to black coloured sclerotial bodies on 4-6 weeks old cultures (Tredway and Burpee, 2001).

The microscopic study also revealed that, the vegetative mycelium of $R$. solani was whitish 
grey when young but became black coloured as it grow and mature. As Rhizoctonia species did not produce spores, it was identified based on the characteristics of hyphae. The hyphae produced branches mostly at right angles and sometimes at acute angles to the main hypha. The branch hypha was slightly constricted at the branch origin and there was a septum near the branch origin (Plate 2). Clamp connection were also seen in rare cases (Plate 3). The fungus also produced monilioid cells in 3-4 weeks old culture. Later these monilioid cells were fused together to produce sclerotia in culture plates. These findings are in agreement with those reported by Kaore et al., (2012); (Dugger, 1915; Dodge and Stevens, 1924; Palo, 1926).

\section{Pathogenicity tests}

Pathogenecity of $R$. solani, the blight causing pathogen in tomato was proved on a highly susceptible cultivar Arka vikas by adopting three inoculation methods (Plate 6) viz., Soil infestation (at sowing), root dip inoculation (at transplantation) and stem application at 15, 30, 45 and 60 days after transplantation. The data pertaining to this study was presented in Table 1.

\section{Soil infestation}

Soil infestation method resulted in preemergence and post-emergence damping off symptoms. In case of pre-emergence damping off, the typical symptoms were observed as rotting of emerging sprouts in soil before emergence and development of necrotic lesions at collar region of the seedlings after emergence. However, the post-emergence damping off symptom appeared at seven days after sowing (DAS) and lead to death of seedlings due to collapse of such seedling. As pre-emergence damping off prevented the tomato seeds to germinate 20 per cent loss in germinability was noticed. Germinated seedlings started showing yellowing of leaves and typical damping off symptoms (Plate 7) with a mean incubation period of seven days (Table 1). Symptom expression in inoculated pots was continued up to 30 DAS with 53.48 per cent of disease incidence (PDI). The pathogen was reisolated from the infected seedlings and the culture obtained was found to be similar with the original culture in all respects.

\section{Root dip inoculation}

Root dip inoculation method was performed by using 28 days old seedlings. The affected seedlings showed typical damping off symptoms with a mean incubation period of two days. However, damping off symptoms were continued to appear up to seven days after transplantation (DAT) which ultimately resulted in 96.67 PDI (Table 1). Initial symptoms appeared as yellowing of older leaves followed by development of light brown lesion at collar region. Later, the tissue at collar region became dark brown to black and lead to death of affected seedlings (Plate 4.8). In some of the seedlings this dark brown to black necrotic lesion extended upwards to the stem delaying mortality in such seedlings.

The pathogen was reisolated from the infected seedlings and the culture obtained was found to be similar with the original culture in all respects (Fig. 1).

\section{Stem application}

As the disease was observed mostly in grown up plants at early flowering and fruiting stage of the crop in farmers fields, this method of inoculation was tried. To prove pathogenecity of $R$. solani at different stages of crop growth stem application was done at 15, 30, 45 and 60 DAT. In this method, blight symptoms were observed up to 30 days after inoculation (DAI). 
Table.1 Performance of inoculation methods in proving pathogenicity of Rhizoctonia solani

\begin{tabular}{|c|c|c|c|}
\hline S. No. & Method of inoculation & $\begin{array}{c}\text { Incubation period } \\
\text { (days) }\end{array}$ & $\begin{array}{c}\text { Per cent Disease } \\
\text { Incidence (PDI) }\end{array}$ \\
\hline $\mathbf{1}$ & Soil infestation & 7 & $53.48(46.96)^{*}$ \\
\hline $\mathbf{2}$ & Root dip inoculation & 2 & $96.67(83.84)$ \\
\hline $\mathbf{3}$ & & Stem application & \\
\hline $\mathbf{i})$ & 15 DAT & 2 & $60.50(51.04)$ \\
\hline ii) & 30 DAT & 3 & $53.33(46.90)$ \\
\hline iii) & 45 DAT & 3 & $46.67(43.06)$ \\
\hline iv) & 60 DAT & 4 & $33.33(34.99)$ \\
\hline $\mathbf{4}$ & Control & & $0.00(0.00)$ \\
\hline & CD at $5 \%$ & 0.94 & 10.68 \\
\hline & S.Em \pm & 0.30 & 3.49 \\
\hline
\end{tabular}

*Figures in parentheses are angular transformed values

Fig.1 Performance of inoculation methods in proving pathogenicity of Rhizoctonia solani
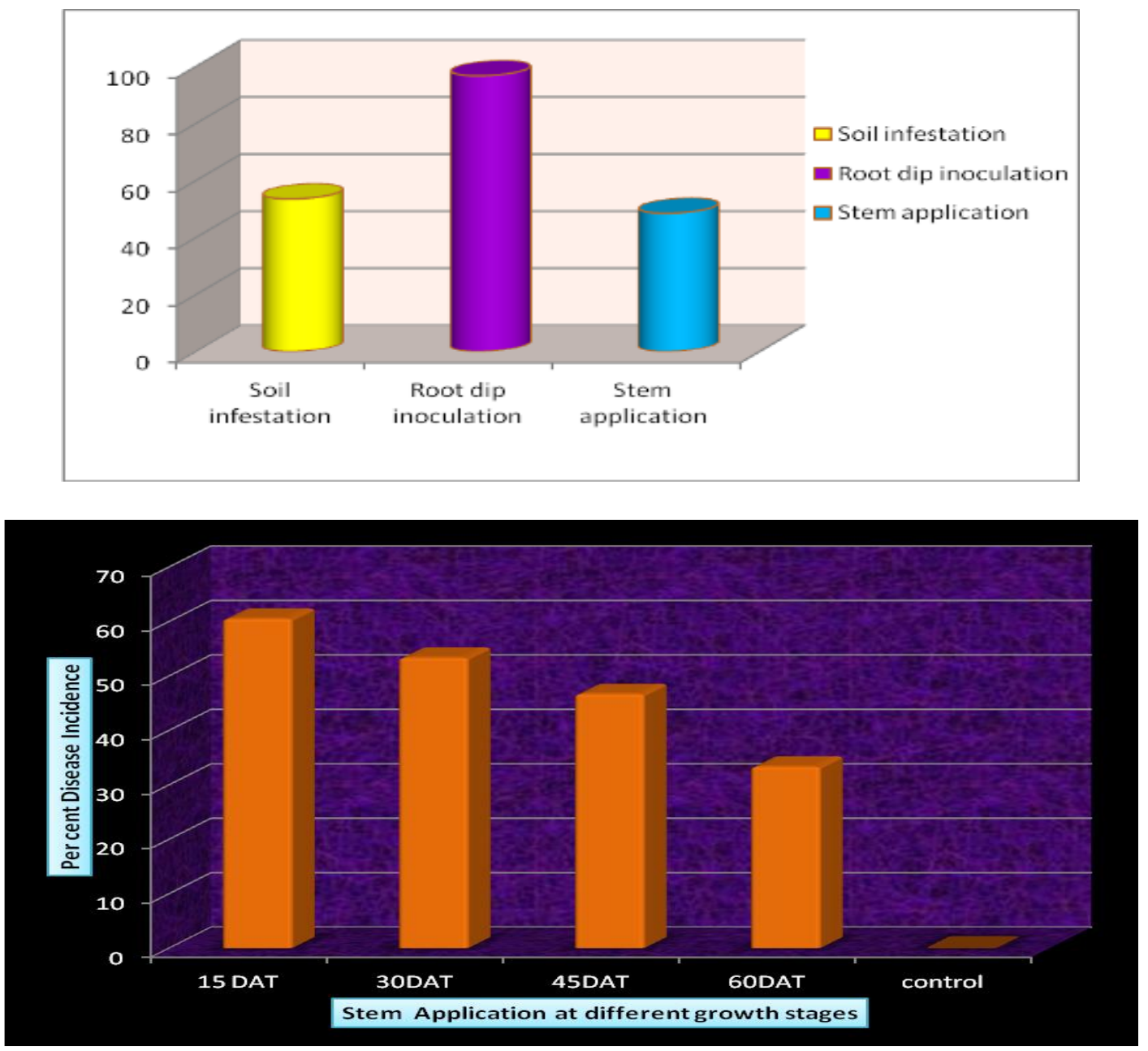
Fig.2 Performance of Stem application in proving pathogenicity of Rhizoctonia solani

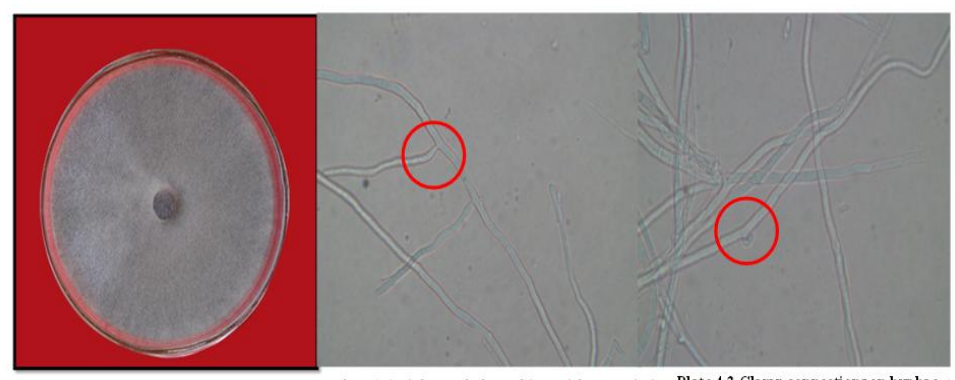

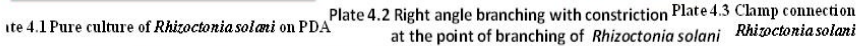

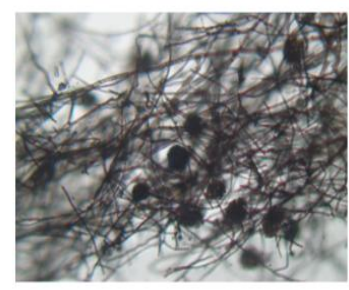

Phte 4.4 Scler otia in old culture of Rhizoctonia solani on PDA

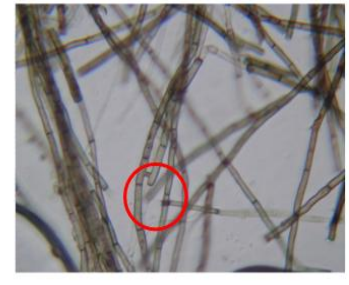

Phate 45 Ana stom osis b etween hyphae of Rhizoctonia

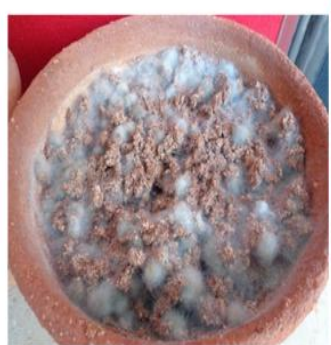

Soil infestation

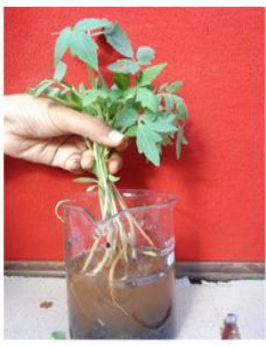

Root dip inoculation

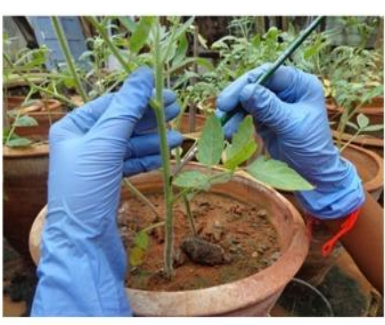

Stem application

Phate 4.6 Methods of inoculation used to prove pathogenicity

of Rhisoctonia solani

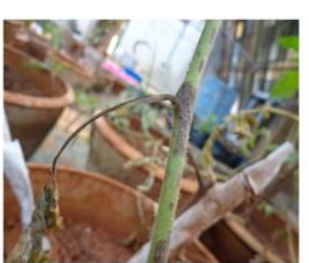

light brown lesions

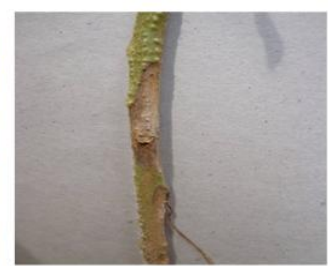

Dry blight symptom

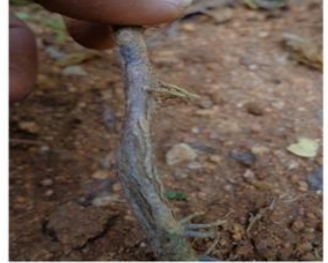

Cracks on bark
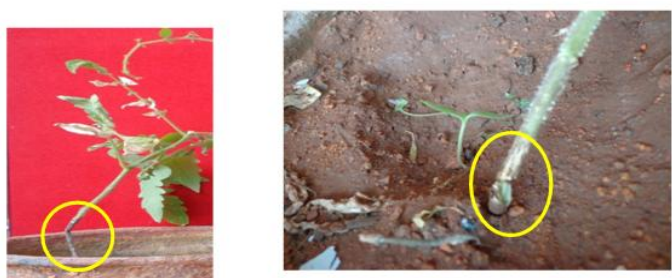

Stem Breaking

Plate 4.9 Symptoms produced by Rhizoctonia Solani through stem application method 
The initial symptoms on inoculated plants appeared as water soaked lesions which later turned to brown and enlarged to become blighted portions. The older leaves on such plants appeared yellow.

The blighted stem portions become dry with typical cracks on them. In some plants, stem at the affected portions break down to cause death of plants (Plate 9).

Plants inoculated at 15 and 30 DAT showed extended blight lesions on stems and resulted in death of plants. Whereas the plants inoculated at 45 DAT and 60 DAT could survive with typical blight symptoms on stems.

The pathogen was reisolated from the infected seedlings and the culture obtained was found to be similar with the original culture in all respects.

There was a direct proportionate relationship between plant age and incubation period. As the age of the plant increased the incubation period was also increased. There was significant difference for incubation period between the different stages of crop growth at which stem applications were done except between 30 and 45 DAT. However, the incubation period was found to be least in plants inoculated at 15 DAT (two days) followed by 30 DAT and 40 DAT (three days) and it was maximum for plants inoculated at 60 DAT (four days).

There was significant difference for PDI recorded at different stages of crop growth when the pathogen was inoculated through stem application method (Fig.2). However, the PDI obtained at 15 DAT (60.50) and 30 DAT (53.33) were non-significant. As the age of the plant increased, there was a decline in PDI recorded. Stem application at 15 DAT resulted in significantly highest PDI (60.50) while that of the least was recorded in inoculation at 60 DAT (33.33) followed by 45 DAT (46.67).

There was significant difference for incubation period and PDI between the methods adopted for proving pathogenicity of $R$. solani and all were found to be effective. However, significantly lowest incubation period (two days) was recorded in root dip inoculation and stem application at 15 DAT followed by stem application at 30 DAT where the incubation period was recorded as three days. The incubation period was significantly highest in case of soil infestation method (seven days) followed by stem application at 60 DAT (four days).

All the inoculation methods used to prove pathogenecity of $R$. solani were found to be effective. Among the methods used root dip inoculation was found to be the most effective with 96.67 PDI followed by that in stem application at 15 DAT (60.50) where the incubation period was recorded as two days. Significantly least PDI was observed in case of stem application at 60 DAT (33.33) with four days of incubation period followed by 45 DAT (46.67) with three days of incubation period. No significant difference was observed for PDI recorded with stem application at 45 DAT (46.67), 30 DAT (53.33) and that recorded with soil infestation method (53.48).

The results are in agreement with studies of Jiskani et al., (2007) who confirmed $R$. solani as the predominant damping off causing fungus while conducting an experiment to prove its pathogenecity on tomato through soil infestation method. These findings are also supported by the observations made by Gordon (2005) who reported the superiority of the root dip inoculation method over soil infestation method while working with a soil borne fungal pathogen. 


\section{References}

Agrios, G.N. 2005. Plant pathology, $5^{\text {th }}$ Edition. Elsevier academic press. London.40-50.

Andy Wyenandt. 2005. Diagnosing and controlling fungal diseases of tomato in the home garden Rutgers Cook College Resource Center. Rutgers Cooperative Research \& Extension, (NJAES), Rutgers. The State University of New Jersey.

Barnett, H.L and Hunter, B.B. 2003. Illustrated genera of imperfect fungi. Fourth edition APS Press, St. Paul, Minnesota. 92-94.

Buttner G., Pfahler, B and Marlander, B. 2004. Greenhouse and field techniques for testing sugar beet for resistance to Rhizoctonia root and crown rot. Plant Breeding. 123: 158-166.

Dodge, B.B and Stevens, N.E. 1924. The Rhizoctonia brown rot and other rots of strawberry. Journal of Agricultural Research. 28: 643-648.

Domand, R. I and Flentji, N. T. 1970. The mechanism and physiology of plant penetration by Rhizoctonia solani. University of California Press. 149-160.

Dugger BM. 1915. Rhizoctonia crocorum (Pers) D C Rhizoctonia solani Kuhn (Corticium vagum $\mathrm{B}$ and $\mathrm{C}$ ) with notes on other species. Annual Missouri Botany Garden. 2: 403-458.

Dutta, S and Dutta, D. 2007. Evaluation of biocontrol potentiality of native plant growth promoting bacteria against Rhizoctonia solani mediated damping off disease of tomato. Journal of Mycopathological Research. 45(2): 201-206.

Gordon, T.R., Shaw, D.V and Larson, K.D. 2005. Comparative response of strawberries to conidial root-dip inoculations and infection by soil borne microsclerotia of Verticillium dahliae Kleb. Hortscience. 40(5):1398-1400.

Gupta, S.C and Kolte, S.J. 1982. A comparative study of isolates of Macrophomina phaseolina from leaf and root of groundnut. Indian Phytopathology. 35: 619-623.

Jiskani, M.M and Pathan, M.A., Wagan, K.H., Imran, $M$ and Abro, H. 2007. Studies on the control of tomato damping-off disease caused by Rhizoctonia solani Kuhn. Pakistan Journal of Botany. 39(7): 2749-2754.

Kaore, N. M., Atul, A. R., Khan, M. Z and Ramnani, V. K. 2012. A rare case of human mycosis by Rhizoctonia solani. Indian Journal Medical Microbiology. 30(3): 361-363.

Kumar, D and Singh, K.P. 2006a Assessment of predatory and effect of Arthobotry dactyloides for control of diseases of tomato. Journal of phytopathology. 154: $1-5$.

Kumar, D and Singh, K.P. 2006b. Variability in Indian isolates of Arthobotry dactyloides Dechsler: a nematode trapping fungus. Current microbiology. 20: $1-8$.

Kumar, V., Haseeb, H and Khan, R.U. 2011. Comparative efficacy of bioinoculents, organic amendments and pesticides against Rhizoctonia solani alone on tomato CV. K-25 under Pot Conditions. World Journal of Agricultural Sciences. 7(6): 648-652.

Latorre and Bernardo. 2004. Enfermedades de las plantas cultivades. Santilago. Ediciones Universidad catolica de chile. 638.

Naz, F., Rauf,C.A., Abbasi, N.A., Irfan-ulhaque and Ahmad. 2008. Influence of inoculum levels of Rhizoctonia solani and susceptibility on new potato germplasm. Pakistan Journal of Botany. 40(5): 2199 -2209. 
Palo, M.A. 1926. Rhizoctonia diseases of rice I. A.study of the disease and of the influence of certain conditions upon viability of the sclerotial bodies of the causal fungus. Philippine Agriculture magazine. 15: 361-376.

Pushapavathi, B., Sireesha, K., Reddy, P.N and Rajender, J. 2013. Prevalence of Rhizoctonia solani blight of tomato in Ranga Reddy District of Andhra Pradesh. 35 ${ }^{\text {th }}$ Annual conference and National symposium on "Innovative and Ecofriendly Research Approch for Plant Disease Management" DP-26.

Rangaswami, G and Mahadevan, A. 1999. Diseases of crop plants in India, $4^{\text {th }}$ edition, Prentice Hall of India Private Limited, New Delhi. 536.

Rifai, M.A. 1969. A revision of genus Trichoderma. Mycological paper. Common Wealth Mycological Institute. 116.

Tredway, L.P and Burpee, L.L. 2001. Rhizoctonia diseases of turfgrass. The Plant Health Instructor. DOI: 10.1094/PHI-I-2001-1109-01.

Upadhyay, K.D and Dwivedi, K. 2008. A text book of plant nematology meerut, India, Aman publishing house.

Wokoma, E.C.W. 2008. Preliminary report on diseases of tomato in choba, Rivers state. Journal of Applied Sciences Environmental Manage. 12(3):117-121.

\section{How to cite this article:}

Sumalatha, N., B. Pushpavathi, R. Jagadeeshwar and Reddy, R.V.S.K. 2018. Studies on Blight of Tomato Incited by Rhizoctonia solani. Int.J.Curr.Microbiol.App.Sci. 7(03): 1050-1059. doi: https://doi.org/10.20546/ijcmas.2018.703.125 